\title{
Teatro e esfera pública: o olhar deChristopher Balme e alguns casos brasileiros
}

Theater and public sphere:the perspective of Christopher Balme and some Brazilian cases

Gustavo Guenzburger ${ }^{1}$ 


\section{Resumo}

O objetivo do artigo é introduzir o estudo das relações entre teatro e esfera pública no Brasil. A argumentação gira em torno da hipótese de que essa abordagem seria capaz de articular a discussão entre teatro e política, tanto no ramo da produção quanto da recepção, especialmente no que se refere ao teatro contemporâneo. A metodologia contém duas etapas: introduz-se alguns pressupostos da teoria de Christopher Balme, a partir da comparação de alguns de seus exemplos com exemplos brasileiros recentes de escrachos e escândalos teatrais, para, ao final, discutir questões referentes ao próprio conceito de esfera pública e sua possivel utilização na realidade teatral brasileira.

Palavras- chave: Esfera pública; teatro contemporâneo; teatro brasileiro; teatro performativo

\section{Abstract}

The aim of this paper is to introduce the study of the relationship between theater and the public sphere in Brazil. The argument revolves around the assumption that this approach would be able to articulate the discussion between theater and politics, both in the production and reception branch, especially with regard to contemporary theater. The methodology includes two stages: the first introduces some assumptions of Christopher Balme's theory, based on the comparison of some of his examples with recent Brazilian examples of riots and theatrical scandals. In the end, questions relating to the concept of public sphere itself are discussed, as well as its possible utilization in the reality of Brazilian theatre.

Keywords: Public sphere; contemporary theater; Brazilian theater; performative theater 
Em março deste ano, em meio à radical divisão política instalada no País, um evento teatral em Belo Horizonte escapole para fora do âmbito fechado da classe e da crítica especializada teatral e de cultura, e atinge todos os canais de comunicação do país, virando assunto inclusive para quem o teatro não é assunto. $O$ Brasil inteiro acompanhou e discutiu nas redes o imbróglio criado quando o ator Claudio Botelho, grande Midas das superproduções musicais, interrompeu uma cena que fazia de seu espetáculo Todos os musicais de Chico Buarque em 90 minutos para incluir um "caco", onde chamava a presidenta Dilma Rousseff de ladra e prognosticava seu impedimento e prisão. Não é necessário aqui comentar detalhadamente a sequência das consequências desse ato: revolta de boa parte da plateia, interrupção definitiva do espetáculo, devolução do dinheiro dos ingressos, vazamento do áudio de uma conversa de camarim entre Claudio e a atriz Soraya Ravenle (ao estilo na moda do jogo político atual), enorme repercussão nas redes, farto espaço em grandes jornais para que Claudio se explicasse, suspensão de (alguns dos) direitos de Chico Buarque para produções de Botelho e, por fim, o pedido de desculpas público do ator e codiretor do espetáculo.

O caso resumido telegraficamente acima é um exemplo, raro no Brasil, do rompimento de um acontecimento teatral para além de sua própria esfera de discussão. Pode ser, portanto, comparado a alguns dos casos europeus analisados pelo professor neozelandês radicado em Munique, Cristopher $C$. Balme, em seu livro The Theatrical Public Sphere (Balme, 2014). Nele, o autor parte de casos contemporâneos e históricos para estudar o que considera ser uma tendência iniciada no século XIX, de desconexão do teatro para com as discussões da sociedade. Segundo sua teoria, a importância política do teatro começa a diminuir a partir da segunda metade do século XIX, com o surgimento do movimento modernista pela aderência teatral a princípios artísticos. $O$ desenvolvimento de salas menores e escuras e a concentração sobre o palco teriam feito com que o foco da atividade teatral migrasse da experiência social para a estética. Para Balme, o espectador do Teatro-Arte modernista "é, idealmente, um decodificador de signos altamente concentrado e um observador autorreflexivo de sua própria experiência" (Balme, 2014, p. 27). Esta tendência de teatro como "caixa preta" teria se radicalizado com o naturalismo do Théâtre Libre de Antoine e depois teria tomado outras formas e seguido pelo mundo afora, na esteira da expansão colonial, e em processos de modernização onde elites locais procuravam modelos europeus. Balme ressalta que, a partir desta nova prática, o teatro enquanto esfera publica começa a se tornar

\footnotetext{
praticamente defunto, salvo um escândalo ocasional, enquanto a dinâmica semiótica em prática no palco-arte transforma todas as coisas em um signo de um signo. Aquelas coisas que resistem a recodificar ou que se mantém, fenomenologicamente falando, obstinadamente en soi - crianças e animais por exemplo - são descartadas ou expelidas do reino. (Balme, 2014, p. 27)
}

Para o pesquisador Neozelandês, o surgimento do teatro-arte modernista teria sido acompanhado por mudanças em condições socioeconômicas e teria acarretado, enfim, uma diferenciação entre plateia e esfera pública (Balme, 2014, p. 14). Ao se 
fechar em ambientes voltados à ideia de arte e de fruição estética, esse teatro teria perdido paulatinamente sua importância na sociedade e também seu caráter público, para se tornar uma atividade privada, com influência restrita. Neste teatro, o espectador perde sua influência nos debates da sociedade e o espetáculo não provoca nele mais nenhuma tomada de consciência quanto ao seu potencial como agente político.

O conceito que Balme utiliza para testar esta sua hipótese apareceu nos anos 1960 em Mudança estrutural da esfera pública: investigações quanto a uma categoria da sociedade burguesa, de Jürgen Habermas (2003). Este livro foca o que Habermas denominou de "esfera pública burguesa", tanto de maneira histórica quanto conceitual. Em termos históricos, trata-se daquela instância de discussão surgida no nascimento da modernidade e nos escombros de uma sociedade feudal, em substituição a um sistema anterior, baseado no mando político absolutista e em formas altamente teatralizadas e cerimoniais de representação pública. A esfera pública burguesa nasce em ambientes como cafés, teatros e clubes, em veículos da imprensa, como uma esfera imaterial (portanto não espacial) e discursiva, através da qual os assuntos da sociedade eram debatidos antes de chegar aos locais de decisão política. Conceitualmente, Habermas define esta categoria pela discussão fundamentada de indivíduos sobre questões de interesse público, com o objetivo de atingir um consenso racional. Esta esfera de debate, que exigiria para seus participantes acesso universal, autonomia de pensamento, igualdade de peso e argumentação crítico-racional, veria seu apogeu no século XVIII e sua degeneração no século XIX e XX, com o processo de comercialização da cultura pelos meios de comunicação de massa e a manipulação política da opinião pública.

Principalmente a partir da tradução para o inglês do livro de Habermas em 1989, a ideia de esfera pública tem sofrido diversas emendas e ataques, sem, no entanto, deixar de ser muito utilizada, ainda que constantemente criticada pela normatividade de sua versão original, idealizada e burguesa-liberal, que vem sendo expandida por noções novas como as de público hegemônico e contra-público. A versão habermasiana do conceito já previa que a interconectividade dos meios de massa garantiriam sua natureza dupla de unidade e fragmentação, onde múltiplas esferas (do teatro, das artes) se ligam de maneira assimétrica e com regras próprias a uma esfera pública maior. No entanto, a partir de 1989, a entrada das questões de gênero, raça, classe e outras na discussão desta ideia aprofundou os estudos sobre sua diferenciação funcional e a formação de diversas esferas públicas. Pesquisadores como Nancy Fraser (2014) têm levantado a questão mesmo da pertinência de tal conceito, após tantas problematizações que este vem sofrendo, seja quanto à dificuldade de desgarrá-lo de sua origem calcada na ideia de estado-nação, seja quanto ao tipo de racionalidade (ocidental hegemônica) que ele supõe como meio, seja ainda, entre outros fatores, quanto ao encobrimento das assimetrias discursivas (embutidas nas diferenças de classes, etnias, raças, etc.) que uma mesma esfera pública pode efetuar.

A conclusão que a leitura de Fraser e de outros estudiosos nos faz chegar é a de que o conceito de esfera pública é um constructo em permanente evolução, discussão e disputa, e que deve se expandir à medida que novas perspectivas lhe são somadas pelo próprio uso empírico de seus postulados, num jogo de ida-e-vinda. Neste sentido, uma das contribuições recentes é o trabalho (citado por Balme) de Chantall 
Mouffe (2000) que, através de exemplos de protestos performativos, mas não de teatro propriamente dito, tenta integrar o afeto e as paixões dentro da discussão sobre esfera pública, preparando o terreno para uma noção estendida deste conceito. A ideia seria que, para além da crítica racional, a esfera pública pudesse comportar o agon, princípio comum que na Grécia antiga conectava a vida da pólis e os festivais teatrais e, segundo Mouffe, seria capaz hoje de reformular a publicalidade, por ser ao mesmo tempo performativo e discursivo. Mouffe argumenta que um "pluralismo agonístico" seria capaz de colocar, pela via da convivência dos afetos, o poder de emancipação da alteridade no centro da prática da democracia. Ao levar em conta e enfatizar o caráter de disputa de qualquer jogo democrático, Mouffe e a escola pósmarxista a que ela se afilia sugerem assim uma alternativa às teorias de democracia agregativa e deliberativa, que levaria muitas vezes a mecanismos de exclusão.

Para Christopher Balme (p. 32), menos argumentação racional e mais emoção não colocaria o princípio do agon do lado oposto ao conceito de Habermas, ao contrário do que a própria Chantall Mouffe pensa. Segundo o neozelandês, o agonístico (no sentido grego mais inclusivo), poderia ser um elo perdido entre uma compreensão de esfera pública racional e orientada ao consenso, onde apenas alguns tipos de falas são funcionais, e um conceito que permite outros modos afetivos de expressão. Além disso, Balme sugere que uma tal síntese entre o modelo crítico-racional e o da escola agonística justificariam a inclusão de manifestações estéticas e expressivas, tais como o teatro, na discussão de esfera pública.

Em seu livro de 2014, Balme discute e acompanha o conceito de Habermas em todas as suas críticas e evoluções posteriores, enquanto tenta aplicar seu escopo teórico a casos do teatro europeu, desde o fechamento dos teatros ingleses no século XVII até algumas performances de nossa década. Diferenciando esfera pública de espaço público, Balme procura entender as causas e os mecanismos que fazem com que o teatro perca importância e eficácia política a partir do século XIX. Para isso ele estuda tanto fenômenos teatrais em espaços públicos, tais como performances e intervenções, quanto espetáculos fechados em prédios de teatro, sempre levando em conta a interação destas manifestações com as diversas esferas públicas em que se inserem, seja por meio midiático ou por interferência direta.

Aparentemente inédito no Brasil, este enfoque que junta teatro e esfera pública promete ser útil pela possibilidade que ele abre de articulação entre elementos estéticos, de recepção e de modos de produção em uma mesma análise do fenômeno teatral. Pode nos ajudar a compreender, por exemplo, as relações entre o esfriamento político do teatro do eixo Rio-São Paulo a partir do final dos anos 70, quando o recuo gradual da censura é concomitante ao surgimento de novas linguagens e de pequenas esferas públicas que se referem às discussões específicas dos vários nichos em que cada vez mais se fragmenta a produção e a recepção teatrais no país.

Para Cristopher Balme, a capacidade de gerar escândalos e de atrair todo o tipo de censura (governamental ou civil) é o termômetro mais fiel da influência que o teatro tem ou pode ter nas discussões de uma sociedade. Em sua visada histórica, o pesquisador mostra como governos e movimentos sociais já foram mobilizados para controlar e censurar a produção teatral, que chegou a representar em alguns momentos uma grande ameaça à ordem pública. Este auge de influência se teria 
dado em torno do século XIX, e envolve diversos fatores: caráter coletivo, potencial de ação política imediata, oralidade que atinge os menos letrados. Balme estuda, por exemplo, o caso da Alemanha de Weimar, onde, após o fim da censura teatral, um surto crescente de ataques às produções por parte de grupos conservadores (de esquerda e de direita) acabou gerando um sistema de regimes diferenciados de censura para teatros "legitimados" e para os populares. Até aquele momento, parecia ser incontornável essa necessidade de censura a formas audiovisuais nas sociedades culturalmente complexas:

O material ofensivo de um grupo é a ideia de entretenimento de uma noite agradável do outro. Meu interesse aqui é explorar como, em situações de pluralismo social, cultural e religioso, os limites de tolerância são policiados de forma assimétrica. A aplicação ou, inversamente, a retenção da censura nos diz muito sobre os sistemas de valores em sociedades abertas e particularmente o grau diferencial com que o pluralismo cultural é de fato reconhecido. (Balme, 2014, p. 143)

Já em sua abordagem contemporânea, Balme mostra que este potencial ofensivo arrefeceu junto com as formas de controle e censura governamental e que, na maior parte dos poucos casos em que o teatro rompe a sua própria camada discursiva (da crítica especializada, blogs, discussões de produtores e públicos especializados) para fomentar um debate mais amplo na sociedade, isto se dá através de escândalos teatrais que acontecem muitas vezes à revelia ou para a surpresa dos próprios artistas criadores.

Este é o caso do musical brasileiro citado acima, que chegou aos jornais, lares e posts de todo o país não por causa de uma proposta artística escandalosa ou de algum elemento cênico ofensivo. A polarização política da população (e da plateia), se juntou ao improviso infeliz e alienado do ator/diretor que, além de todo o resto, ainda ignorou o fato de que, sendo as músicas de autoria de um dos artistas que mais defendem o governo de Dilma Rousseff, o espetáculo poderia atrair uma plateia de simpatizantes do governo. Ou seja, uma conjunção de fatores extra-teatrais atuou para sua interdição pela plateia e consequentemente para a geração do escândalo teatral, em sintonia com o clima da sociedade.

Balme define o escândalo teatral como a transgressão de uma norma, que produz uma reação emocional violenta do público e muitas vezes termina em sanção legal. É uma quebra daquele contrato entre espectadores e artistas que garante aos primeiros o direito de aprovar ou reprovar, vaiando ou aplaudindo. O escândalo acontece quando esta resposta perturba a paz. Uma plateia decide quebrar o acordo e incluir outros agentes sociais: polícia, jornais, redes sociais, "[...] em outras palavras, o teatro não cabe mais na caixa preta da recepção estético-teatral." (Balme, 2014, p. 140) A inclusão da esfera pública faz com que esta visão ultrapasse aquela tradicional, do esquema modernista para o escândalo, que o enxerga apenas como processo dialético de tese (norma) antítese (obra transgressora) e síntese (nova norma). Apesar de no caso da Alemanha de Weimar a transgressão estética de alguns espetáculos ter servido como estopim para algumas manifestações daquilo que iria desembocar em um movimento (fascista) de repressão social sobre o teatro, Balme defende que ali o esquema modernista não é suficiente para compreender o quadro completo dos cer- 
ca de 100 escândalos do período, dado o papel apenas periférico que a transgressão estética exerceu dentro de um processo maior, este sim capaz de revelar as fissuras e tensões de uma sociedade fraturada: divisões de classe, religião, etnias e política. (p. 145) No caso de Todos os musicais de Chico Buarque em 90 minutos, a transgressão é mesmo difícil de se encontrar dentro do espetáculo, que se liga ao mercado de entretenimento e não tem pretensões políticas ou de inovação estética. No entanto, a comoção que a fala improvisada de seu ator principal causou nos meios midiáticos teve o mesmo poder de revelação de fraturas sociais.

O escândalo brasileiro ainda teria menos repercussão se outro fator extra-palco não tivesse sido acionado. Espelhando o clima de conspiração do momento político atual (operação Lava-jato/impeachment), onde qualquer conversa ou reunião pode estar sendo gravada para ser usada como prova, o alvoroço foi potencializado pelo vazamento e viralização da gravação ilegal de uma conversa de camarim entre Claudio Botelho e a Atriz Soraya Ravenle. Para além da discussão sobre posições políticas ou um possível racismo nesta conversa gravada, o interesse que seu conteúdo suscita para a atual análise vem da explicitação da ideologia privatista que ela revela, a partir do momento em que a atriz tenta argumentar com o colega. "Mas a plateia tem direito de vaiar, você provocou, você continuou desafiando". Claudio então contra -argumenta de várias formas, inclusive comparando o incidente com a censura que o espetáculo Roda-Viva (de Chico Buarque) teria sofrido nos anos 60. Mas aqui nos interessa a imagem que o criador Botelho tem de um palco como lugar de fruição passiva, dentro de um teatro enquanto instituição privada: “Um ator que está em cena é um rei! Não pode ser peitado. Não pode ser peitado por um nego, por um filho da puta que está na plateia. Não pode. Não pode ser peitado. Eu estava fazendo uma ficção [...]. Pega seu dinheiro de volta. Essa peça é minha."

Racismo, blasfêmia, homofobia e outras agressões a grupos identitários ou religiosos são os principais detonadores atuais desse tipo de ruptura de contrato entre espectadores e artistas, tanto nos casos europeus citados por Cristopher Balme quanto em alguns ainda poucos casos recentes no Brasil. Mas o que ressalta dos casos contemporâneos estudados pelo neozelandês é que, ao contrário do teatro produzido na época da Alemanha de Weimar, a ofensa (em geral involuntária) causada por um espetáculo de hoje não resulta apenas do choque de visões de mundo diferentes entre grupos culturais diversos. Na maioria das vezes, e nos mais variados estilos e correntes artísticas, o potencial agressivo (e, portanto, escandaloso) de uma representação decorre justamente da noção privatista que se tem da atividade teatral.

O que Balme consegue demonstrar em seus exemplos é que justamente a vontade de ser uma caixa preta fechada, território livre tanto para a ficção (ou quebra dela), como para o discurso (ou sua negação), faz com que o que se diga ou se faça no palco seja pensado na maioria das vezes como algo que só diz respeito ao palco, como as tintas de um quadro, e que assim deve ser visto por todos que ali estiverem para assistir. Mas nem sempre este efeito esperado é o que acontece, independentemente das pretensões de entretenimento, caixa fechada, ou fruição exclusivamente estética. Balme cita como exemplo disso o caso de $A$ Casa de Bonecas que, ao contrário das pretensões de lbsen, foi vista como símbolo da luta pela libertação das mulheres. O pesquisador neozelandês dá destaque a casos de espetáculos que desta 
forma, sem querer ou alienadamente, acabaram incomodando e sendo interditados por grupos antirracismo, grupos religiosos etc.

Um caso paradigmático deste mecanismo é o da montagem de 2003 da ópera Idomeneo de Mozart, em que a concepção do diretor Hans Neuenfels incluía um epílogo a título de comentário artístico contemporâneo, onde uma cabeça decapitada do profeta Maomé era exibida ao lado das cabeças decapitadas de Jesus, Posseidon e Buda. Em uma remontagem de 2006, o contexto europeu já havia sido modificado em uma escalada de tensão que começara pela reação violenta a caricaturas de Maomé feitas em um jornal dinamarquês (precursor do Charlie Hebdo) de declarações do Papa Ratzinger pessimamente recebidas pela comunidade muçulmana, e da criação do primeiro conselho islâmico alemão. O resultado disso foi que a reestreia em Berlim acabou sendo cancelada, depois de uma denúncia anônima de bomba. Mesmo ocorrendo no pós-11 de setembro, nem os criadores e produtores e nem a crítica especializada haviam sido capazes de prever o potencial de blasfêmia do espetáculo, apesar de, na Alemanha, isto ser um crime previsto em Lei:

Com sua apresentação alternativa das cabeças decapitadas dos deuses, Neuenfels criou uma metáfora visual, um exemplo estilisticamente típico de um diretor alemão que é conhecido pelo uso de figuras "fortes", de interação figurativa, sem uma motivação intrínseca clara com a obra propriamente dita. Estas metáforas não devem ser tratadas meramente como "lixo europeu", mas lidas enquanto metacomentários diretoriais e dramatúrgicos projetados para sublinhar a relevância contemporânea de uma obra clássica. A reação da crítica em 2003 revela a eficácia de tais metáforas, na medida em que não existiu consenso sobre o que a nova cena queria dizer. Críticos forneciam diferentes leituras, e estavam unidos apenas na indiferença para o conteúdo potencialmente blasfêmico da imagem. As resenhas publicadas depois da estreia revelam uma lista de interpretações que vão desde cabeças como troféus, ópio como religião do povo, deuses como ídolos e um comentário sobre "O Embate entre Civilizações", de Huddington. Em nenhuma das 23 resenhas pesquisadas - a maioria das quais críticas à cena por motivos estéticos - aparece a palavra blasfêmia. (Balme,2014, p.129)

Depois da denúncia anônima, a decisão da Ópera de Berlim de suspender a reestreia do espetáculo também foi criticada pelos meios culturais e pela mídia, e vista como uma capitulação dos responsáveis frente a uma inaceitável tentativa de cerceamento à liberdade artística. A ideia de que o conteúdo imagético do espetáculo pudesse ser ofensivo a toda uma população de imigrantes e cidadãos alemães islâmicos continuou fora do debate, que se centrou sobre a liberdade de expressão e de criatividade.

Balme ressalta que, embora o diretor Hans Neuenfels seja ligado à oposição, se sentiu bem ao ser defendido por políticos como Ângela Merkel (que se esforçou durante anos para evitar uma nova lei de imigração mais flexível). Ao defender a liberdade da arte acima de uma ofensa potencial ao Islã, os artistas não notaram que sua posição já tinha perdido qualquer possível característica autônoma que porventura tivera antes. Ela tinha se tornado politicamente instrumentalizada e o princípio de liberdade artística serviu a uma agenda anti-multicultural. Idomeneo acabou trabalhando para reavivar e reforçar este tipo de pensamento que serve ao exercício da autoridade, ao colocar o oriente (Islã) como inimigo da liberdade de expressão, embora a denúncia da bomba nunca tenha se confirmado (ficou como um boato) e as 
reações do mundo islâmico à controvérsia tenham sido na realidade muito pequenas.

Dois outros exemplos que Balme aborda de escândalos involuntários tratam do problema da discussão do racismo e o teatro. O primeiro diz respeito ao espetáculo I'm not Rappaport, que aconteceu no Schlossparktheater, um teatro privado onde se apresentam atores de visibilidade na mídia. Nesta montagem de 2012, o papel do zelador foi feito por um ator branco, o mesmo que o tinha feito na estreia em idioma alemão em 1987. Quando o cartaz da peça apareceu na página de facebook do teatro, a maquiagem (máscara negra) do ator desencadeou uma reação em cascata do tipo que havia sido recentemente apelidado como shitstorm (nosso escracho online). O diretor do teatro se defendeu dizendo que não havia atores negros disponíveis que falassem alemão perfeito, e que o editor do texto não teria permitido um ator negro nesse papel, por "ferir o contexto do autor". A discussão via página de Facebook variou da crítica racional à agressão e ao cinismo, e o debate deu chance ao teatro de se defender das acusações: o que fazer com Turandot, Otelo, Alma boa de Sezuan quando não tivermos um negro ou um asiático em nosso elenco? $O$ teatro Scholossparktheater, com pouco patrocínio governamental, decidiu levar adiante o espetáculo mas retirou o cartaz, e a temporada foi um sucesso que durou o ano inteiro. Mas a polêmica serviu para inaugurar o debate sobre o tema, que teve repercussão de longa duração, com a criação do que Balme identifica como um contra-público organizado como grupo (Bühnenwatch - De olho no palco) em torno da vigilância ao racismo no teatro.

Em sequência, o grupo (composto por "ativistas 'de cor' e brancos ativistas") voltou suas atenções para uma produção do Deutches Theater, o mais prestigioso e bem subsidiado teatro de Berlim. A peça Unschuld (Inocência) já estava em cartaz há muitos meses, mas a partir desse momento demandava uma intervenção crítica similar. Dois de seus personagens eram africanos e o autor recomendava que só fossem representados por atores negros se estes fossem bons atores; caso fossem feitos por atores brancos, nada de maquiagem Black face. Mas o diretor do espetáculo não seguiu a recomendação, e caprichou na cara preta e lábios vermelhos. Na sessão de 12 de fevereiro de 2012, quando os dois atores alemães entraram em cena, 42 espectadores levantaram e saíram da plateia coletivamente, e distribuíram panfletos no foyer. A direção do teatro agendou um encontro com os manifestantes para discutir o assunto. No começo, o diretor se mostrou irritado e afirmava que o dispositivo da maquiagem tinha o objetivo justamente de desconstruir o racismo ao apontar sua penetração na Europa (tanto em geral quanto em relação às tradições de representações racistas do teatro). Dispensar a maquiagem seria renunciar a um símbolo visual central, a uma afirmação da montagem, e significaria uma ameaça à liberdade de expressão artística. Em seu panfleto, o grupo de ativistas já tinha antecipado sua crítica a esse argumento, rejeitando o dispositivo como um efeito de alienação simplista. Por fim, o teatro acabou aceitando a sugestão dos manifestantes de trocar o Black face por uma exagerada White face, que para o diretor não afetaria a intenção do espetáculo e deixaria de ferir a sensibilidade de parte da plateia.

Balme ressalta que a solução de pintar a cara dos atores de branco chama a atenção para o impasse de representação da alteridade no palco alemão, uma sociedade com grande população estrangeira e não-branca. $O$ novo dispositivo também 
representou um metacomentário ao sucesso da pressão do grupo Bühnenwatch, ao fracasso do dispositivo anterior e à possibilidade de a esfera pública interferir em uma instituição forte e politicamente sensível como o Deutches Theater - o que vale também para o caso de I'm not Rappaport:

Embora o debate público tenha produzido resultados mistos - em ambos os casos, as produções continuaram com as mesmas estruturas semióticas - ele demonstrou o poder da esfera pública para intervir, e de fato ensinar ao mundo um tanto hermético do complexo e muitas vezes autorreferencial sistema teatral alemão que as questões raciais eram endêmicas no próprio sistema, e que não poderiam ser simplesmente desativadas por uma mudança de maquiagem. (Balme, 2014, p. 173)

Em um caso, o debate se deu na própria rede, onde o teatro particular fazia sua divulgação. No caso do teatro público, com um site menos permeável à participação online, os manifestantes atuaram diretamente na plateia, embora organizados via redes, e assim permanecem atuando ("observando os palcos") até hoje.

Além do escândalo de Todos os musicais de Chico Buarque em 90 minutos, dois casos recentes no Rio de Janeiro e em São Paulo chamaram a atenção da imprensa e das redes ao desencadear, de forma inadvertida, vigorosos debates também sobre o racismo e a representação do negro na sociedade brasileira. Em junho de 2015 o espetáculo João Alabá e a Pequena África foi alvo de protestos virtuais antes de sua estreia na região da Pedra do Sal, por retratar uma personagem mãe de santo do início do século $X X$ através de uma atriz branca. Os protestos nas mídias do espetáculo começaram quando a foto da atriz Cristiana Ubach, paramentada como a personagem mãe de santo, saiu em uma coluna social do jornal O Globo (Kogut, 2015). Em sua justificativa, o autor e diretor da peça Alexei Waichenberg ressalta o argumento do ficcional, tenta se identificar e se legitimar como um branco praticante de religião afro-brasileira e, por fim, demonstra algum desconhecimento sobre a luta das afirmações identitárias e de memória em que se engajam grupos de consciência negra, especialmente sobre o legado histórico do entorno da região da Gamboa e Pedra do Sal, local onde a peça iria estrear:

Mãe Wanda de Omulu é uma personagem fictícia, inspirada na Yalorixá que cuida das minhas convicções religiosas, inspirada nos estudos que eu e minha equipe vimos fazendo para encenar importantes fatos e destacar importantes personalidades da história da formação da sociedade carioca... (Romão, 2015)

A peça, que tinha patrocínio da Light e fazia parte do Projeto Porto de Memórias (uma das raras iniciativas teatrais que acompanham a reurbanização da área), foi cancelada e só estreou depois de negociações com os movimentos negros, que incluíram a substituição da atriz citada por Kenya Costta, além de mudanças no roteiro.

Um mês antes deste evento, a cia paulista Os Fofos Encenam já havia interrompido sua temporada de $A$ Mulher do Trem para dar lugar a um debate aberto ao público e com a participação de ativistas para discutir problemas de racismo e representação, desencadeados pela denúncia do uso de Black face no espetáculo. A acusação de racismo soou esdrúxula para a companhia, uma vez que esta era uma remontagem de um texto com o qual ela tinha sido premiada nove vezes em 2003, incluindo um prêmio Shell. O uso do Black face em uma personagem subalterna como parte de um 
dispositivo cênico que comentava certo tipo de dramaturgia antiga, melodramática e marcada por preconceitos de época pode ter soado engraçado ou poético doze anos antes, mas depois de junho de 2013, saltou aos olhos como um descolamento da realidade dos embates sociais que afloraram e passaram a fazer parte da discussão cotidiana na sociedade brasileira.

Por causa do estágio preliminar da presente pesquisa no assunto, até aqui este trabalho se limitou a indagar, através de exemplos e da análise do mecanismo do escândalo teatral feita por Christopher Balme, sobre como o problema da marginalização política do teatro poderia ser pensado também no Brasil. Por enquanto, acompanhamos a tese de Balme, segundo a qual este processo seria desencadeado por condições de dentro e de fora da criação teatral, sejam históricas, socioeconômicas ou midiáticas, e provocaria em diferentes faixas do teatro a busca por modos alternativos de apresentação ou o fechamento cada vez maior em um mundo estético e autorreferencial. Apesar de correr o risco de fazer o presente trabalho se parecer com uma resenha, o fato de tal olhar ser capaz de abranger criação, recepção e contexto sócio-econômico e cultural no estudo do teatro parece ser suficiente para justificar este tipo de perspectiva nos estudos teatrais brasileiros, não apenas como recurso epistemológico mas também no intuito de ajudar o meio teatral (artistas, crítica, produção, mercados) a desconstruir um biombo que muitas vezes o separa de outros meios discursivos de nossa sociedade.

No entanto, para concluir este trabalho que se pretende uma introdução crítica ao pensamento de Christopher Balme sobre as relações entre teatro e esfera pública e suas possibilidades para teatro brasileiro, faz-se necessário tocar na questão teatral contemporânea que suscitou este novo olhar. Trata-se da insurgência do elemento performático. Segundo Christopher Balme, a perspectiva performática tem por princípio próprio a tentativa de alcançar a esfera pública, ao assumir que esta não tem os mesmos contornos de uma audiência teatral - o que obriga o pesquisador a investigar a dinâmica do teatro em aspectos exteriores ao aqui-agora da apresentação. Neste aspecto, Balme afirma que seu livro difere das discussões de Hans Thies-Lehmann (2007) e Erika Fischer-Lichte (2008) sobre experiências recentes que, para o neozelandês, se fecham na caixa preta modernista de comunicação teatral e no encontro direto entre artistas e espectadores (autopoietics feedback-loop), apenas enquanto gerador de experiência estética e com pouco debate social ou político. (Balme, 2014, p. 13). Contra isto, a proposta de Balme envolveria

[...] uma mudança de perspectiva para longe da fixação modernista e pós-modernista na temporalidade eventual da dimensão estética do teatro - o evento - e um retorno e um realinhamento com questões de imbricação social e política, que transcendem qualquer ocasião performativa particular. (2014, p. 13-14)

Alguns problemas se colocam a partir desta oposição que Balme faz de sua perspectiva e do trabalho de Lehmann e Fischer-Lichte. Em primeiro lugar, embora os dois pesquisadores alemães abordem em geral exemplos do teatro, eles utilizam enfoques diferentes (o fim do drama e a produção de presença) que provocam em seu trabalho posições diferenciadas sobre a inserção do teatro na cultura e na sociedade contemporâneas. 
Hans Thies-Lehmann (2007) finaliza seu livro sobre o teatro "pós-dramático" com um capítulo sobre a possibilidade de esta nova arte do palco intervir politicamente como antídoto às mazelas da sociedade massificada pela mídia, em consonância de certa maneira com o antigo projeto modernista de redenção da vida moderna através da cultura. Neste campo o autor se aproxima de pensadores da arte como Jacques Rancière, e do que Bérénice Hamidi-Kim chama de "Théâtre Poélitique". Mas também aproxima o pós-drama do ideal de Lessing e dos criadores do drama burguês, ao conferir de novo ao teatro a tarefa de "educação dos sentidos" - não mais a educação para os princípios da ética e da vida burguesa, mas uma reapropriação da própria faculdade de sentir. O teatro da presença, significante sem significado, deveria ser uma alternativa ao mar de imagens realistas da mídia, que sobrecarrega a sensibilidade do público a ponto de embotá-la. Por seu lado, o drama, migrado para a mídia e para a indústria cultural, exerceria hoje, ao contrário da época de Lessing e Schiller, uma força conservadora na fabricação desta babel de imagens e discursos, ajudando a forjar um mundo onde o discurso e a política não têm mais sentido. Portanto, sem possibilidade de um discurso contra as imagens, o pós-dramático de Lehmann proporia uma interrupção da política atuante neste mundo, ao opor a ela a resistência do não-discurso, da criação de novas sensibilidades

A oposição de enfoques entre Balme e Lehmann transparece na escolha que o primeiro faz, em seu livro, de exemplos de performances que conseguiram incorporar mecanismo midiáticos em suas poéticas e assim furar a barreira que separa a esfera pública estritamente artística (crítica, audiência, artistas) da esfera pública mais ampla de discussão da sociedade. Um dos exemplos mais criativos, instigantes e bem-sucedidos nesse sentido prece ter sido o da performance austríaca Please Love Austria!, que usava um dispositivo de reality show em que imigrantes à procura de asilo conviviam dentro de um container posicionado em praça pública e televisionado via internet, sendo o público online o responsável por votar naquele participante que seria deportado na próxima rodada. Paralelamente ao programa, por cima do container, debates sobre assuntos relacionados à imigração aconteciam com a presença de intelectuais e pessoas conhecidas. A polêmica suscitada por esta performance/programa atingiu boa parte da Europa e chamou a atenção para a escalada de ascensão dos partidos políticos de estrema direita não só na Austria, mas em todo o continente, trabalhando a partir da superexposição irônica dos mecanismos midiáticos que simplificariam e despolitizariam o assunto da imigração a ponto de este ser considerado um problema exclusivo dos exilados, ou de como se livrar deles.

Apesar de ir no caminho contrário à proposta do teatro pós-dramático de Lehmann, de interrupção da política através da interrupção da torrente de informações e imagens midiáticas, esta performance analisada por Balme não difere completamente de uma ideia de reeducação de sentimentos, ao fazer uma crítica velada aos mecanismos midiáticos que ela mesma incorpora. A diferença, neste caso, pode estar mais nos meios do que nos fins.

Além disso, a escolha desta performance austríaca por Balme também revela que talvez sua abordagem não exclua totalmente a possibilidade de interação com o outro escopo teórico de que ele faz questão de se diferenciar. Erika Fischer-Lichte localiza em geral sua análise no processo de produção de presença, na experiência 
pessoal resultante da interação entre performance e espectador e nas consequências destes processos do aqui-agora do evento performático. Neste sentido seu foco talvez tivesse pouca eficácia sobre uma performance mediada e midiatizada como Please love Austria!, em que contexto e efeito socioculturais são talvez tão importantes quanto o momento da apresentação em si. Por outro lado, um mecanismo chave desta performance, que desencadeia tanto o interesse da plateia quanto o dispositivo irônico, é justamente a indecidibilidade do estatuto dos participantes do jogo, entre sua condição de exilados reais ou de atores em um jogo ficcional. Um tal dispositivo não só está previsto na teoria de Fischer-Lichte sobre o teatro performativo contemporâneo, como é apontado por ela como sendo o próprio sistema que o delimita, enquanto um jogo equilibrado e indefinido entre representação (sentido) e presença. (Fischer-Lichte, 2013)

Se quisermos introduzir esta nova e rica abordagem nos estudos brasileiros, é importante lembrar que talvez o foco sociocultural necessário ao estudo da esfera pública atrelada ao teatro não exclui necessariamente outros olhares, mais voltados ao evento performático em si. Apenas o estudo aprofundado das novas poéticas pode evitar que a pesquisa caia na armadilha de uma arte contemporânea que sabe muitas vezes se alimentar e se sustentar midiaticamente por escândalos. Provavelmente esses outros olhares podem enriquecer a discussão reivindicada por Balme quanto à expansão do próprio conceito de esfera pública, e principalmente de sua problemática adaptação a meios externos à cultura europeia hegemônica a partir do qual ele foi histórica e teoricamente forjado por Habermas. No caso brasileiro, será mais que nunca necessária uma noção expandida de esfera pública, que leve em conta as heterogeneidades e assimetrias de nossa sociedade e mais especificamente de nossos diversos fazeres teatrais.

A pesquisadora inglesa Janelle Reinelt (2011) ressalta a dificuldade que o teatro e as artes no mundo inteiro encontram para atingir a esfera pública na medida em que são sustentadas por governos ou pelo mercado globalizado. É preciso, no entanto, que busquemos compreender as especificidades brasileiras no que diz respeito a uma atividade cada vez mais dividida entre um mercado altamente lucrativo de entretenimento e uma produção mais artesanal e mesmo semi-diletante, cada vez mais dependente de seu relacionamento com verbas e espaços municipais. O dinheiro estatal une estes dois (ou vários) mundos teatrais, embora isso aconteça de maneira desigual e, no caso do entretenimento subsidiado pelas políticas de incentivo fiscal integral, como a Lei Rouanet, de maneira camuflada e distorcida. Paralelamente, com a chegada de novas camadas sociais ao fazer teatral, novos modos de produção começam a aparecer, embora na maioria das vezes também voltados (ainda que em formas alternativas) ao patrocínio estatal. Apesar disso, a contínua diminuição de público, salas e verbas para espetáculos fora do circuito comercial de grandes musicais ou nomes televisivos, leva à constatação do esgotamento de um modelo em que o teatro é compreendido como um evento que interage com uma única esfera pública mediada por veículos de comunicação e por instâncias de legitimação como crítica especializada, comissões de prêmios etc.

Em todo o país, movimentos sociais de artistas (Arte contra a Barbárie, Redemoinho, Reage Artista!, OcupaMinc) cada vez mais vêm tomando consciência de que os 
diversos teatros precisam se relacionar com outras formas de redes e de esferas públicas, para fora da lógica do evento de retorno midiático que encara o público como uma esfera homogênea. Para tanto, novas mídias podem até ser exploradas dentro das poéticas teatrais e performáticas, como sugere Balme. Mas no caso brasileiro, parece urgente para muitos criadores destas e de outras poéticas que se comece a encarar sua produção, subsídio, criação e difusão como processos de longa duração e com algum tipo de ligação geográfica e/ou comunitária que as conecte a outras esferas e redes.

Se não separar o estudo das poéticas de outras questões como esfera pública e inserção socioeconômica, a pesquisa teatral brasileira também poderá ter um papel preponderante nesta mudança de compreensão, que poderia favorecer ao mesmo tempo uma sobrevivência mais digna dos artistas, sua liberdade de criação e uma inserção mais eficaz de seu trabalho nas diversas esferas de discussão da sociedade.

\section{Referências}

BALME, Christopher C. The Theatrical public sphere. Cambridge University Press, 2014.

FISCHER-LICHTE, Erika. The Transformative Power of Performance: A New Aes thetics. London/New York: Routledge, 2008

Realidade e ficção no teatro contemporâneo. Sala Preta. São Paulo. v.13-2, p.14-32, 2013. Disponível em http://www.revistas.usp.br/salapreta/arti cle/view/69073. Acesso em: 30 abr. 2016.

FRASER, Nancy. Transnationalizing the Public Sphere: On the Legitimacy and Efficacy of Public Opinion in a Post-Westphalian World. Theory Culture Society 2007; 24; 7. DOI: 10.1177/0263276407080090. Disponível em http://www.so ciol.unimi.it/docenti/barisione/documenti/File/2008-09/Fraser\%20(2007)\%20 -\%20Transnationalizing\%20the\%20Public\%20Sphere.pdf . Acesso em: 30 abr. 2016.

HABERMAS, Jürgen. Mudança estrutural da esfera pública: investigações quanto a uma categoria da sociedade burguesa. Rio de Janeiro: Tempo Brasileiro, 2003.

HAMIDI-KIM, Berenice. Les cités du théâtre politique en france depuis 1989. Montpellier: Éditions l'Entretemps, 2013.

KOGUT, Patrícia. História Carioca. O Globo. Rio de Janeiro, 12 jun. 2015, p. 5 Disponível em: http://kogut.oglobo.globo.com/noticias-da-tv/coluna/noti cia/2015/06/segunda-temporada-de-conselho-tutelar-sera-exibida-no-uni versal-depois-da-record.html. Acesso em 30 abr. 2016. 
LEHMANN, Hans-Thies. O teatro pós-dramático. São Paulo: Cosac Naify, 2007.

MOUFFE, Chantall. Deliberative Democracy or Agonistic Pluralism. Political Science Series, v.72, p.1-30, 2000.

REINELT, Janelle. Rethinking the Public Sphere for a Global Age. Performing Pu blics v. 16 (2), p.16-27, 2011. Disponivel em: http://www.tandfonline.com/doi/ab s/10.1080/13528165.2011.578724. Acesso em 30 abr. 2016.

ROMÃO, Marcos. Artistas negras somem da paisagem do Rio de Janeiro de 2015. Artistas negras protestam na Pedra do Sal. Mamma Terra, 14/jun. 2015. Dispo nível em: https://mamapress.wordpress.com/tag/ato-contra-peca-racista-jo ao-de-alaba-e-a-pequena-africa/. Acesso em 30 abr. 2016.

Recebido em: 30/04/2016 Aprovado em: 16/07/2016 